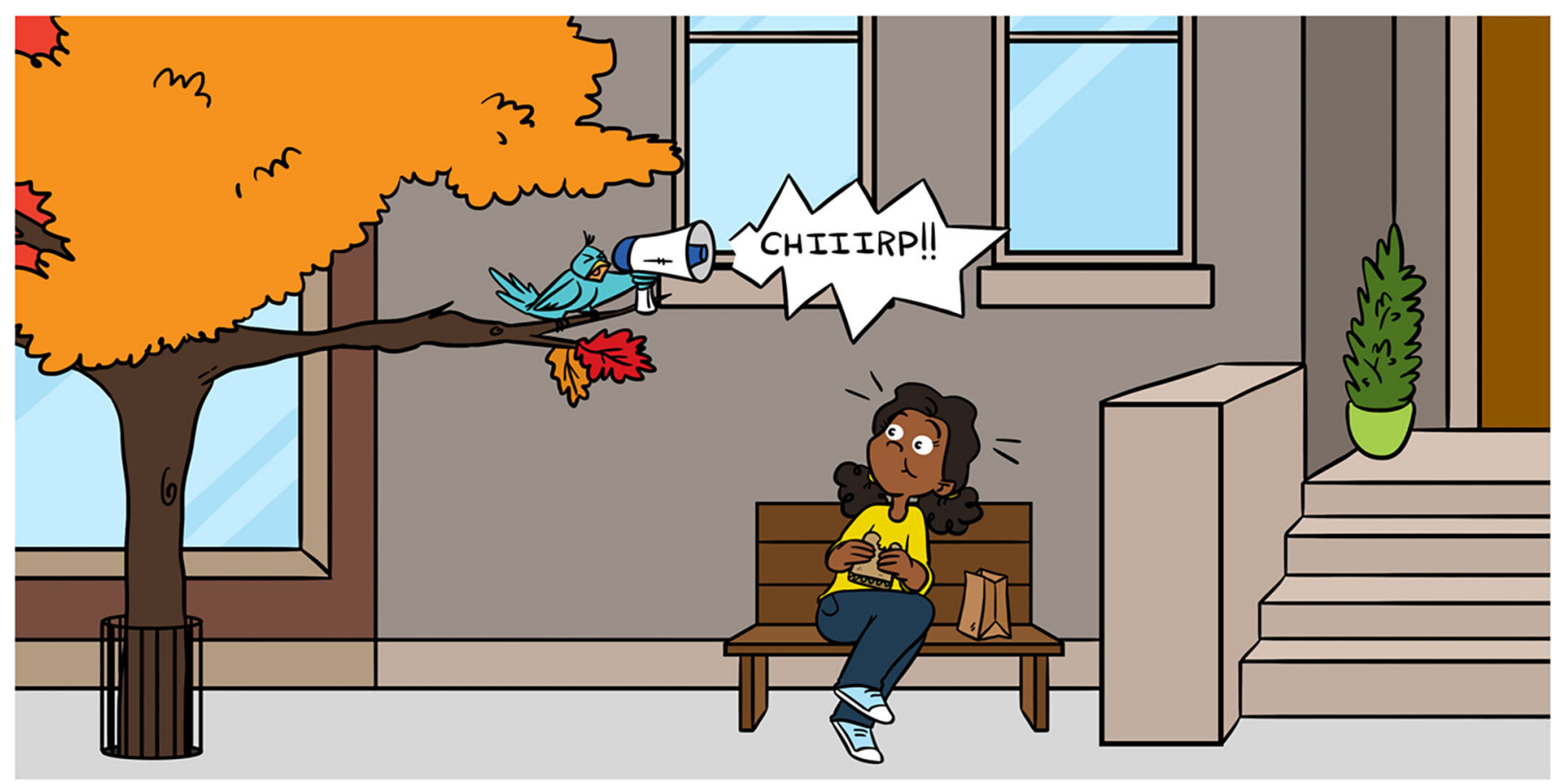

\title{
HOW DO BIRDS SING OVER CITY NOISE?
}

\section{Nyssa Kantorek, Abigail Searfoss and Nicole Creanza *}

Department of Biological Sciences, Vanderbilt University, Nashville, TN, United States

YOUNG REVIEWER:

DOROTHY

AGE: 9
Have you ever raised your voice because someone could not hear you? Imagine talking to a friend in a peaceful park. Now imagine trying to talk on a busy street or near a highway. The traffic noise makes it difficult to communicate, and you may speak up so your friend can hear you. Other animals have this issue, too. Songbirds can live in various environments, such as forests and grasslands, and they use their songs to communicate with each other. As cities grow and invade their habitats, birds may find it harder to hear one another. To be heard, some birds might change their songs. For example, some birds in cities sing louder, longer, or at a higher pitch than rural birds. Researchers are studying this problem: how does human-made noise affect birdsong? Answering this question is important so we can protect the birds around us and their habitats.

\section{WHY DO BIRDS SING?}

As people, we speak to each other to communicate or relay information. Birds are not that different from us; they communicate with each other through calls and songs. While humans push air from their lungs through their vocal cords to speak, birds make sounds by 
Figure 1

A male American robin Robins' songs can sound like "cheerily, cheer up, cheerily, cheer up"1. American robins live in many parts of the United States, so many people living there may see and hear them in their backyard every day. The graph shows the robin's song and can be read kind of like reading sheet music. The $x$-axis shows time, so the graph is read from left to right. The $y$-axis shows the pitch, similar to the way musical notes are written on a staff at different heights.

1 Here is an American robin recording contributed by Eric Zawatski, audible at the 1 second mark: https://www.xenocanto.org/559314.

\section{SYRINX}

"Voice box" organ found in birds that produces sound with vibrations caused by air flow.

\section{SONGBIRDS}

Birds that have the anatomy to support (usually melodic) song.

\section{POPULATION}

Members of a species living in the same area. OSCINE

The group of songbird species that learn their song from adults in their population.

\section{SUBOSCINE}

The group of songbird species capable of producing song without help from adults.

\section{URBAN}

Related to a city or densely populated area.

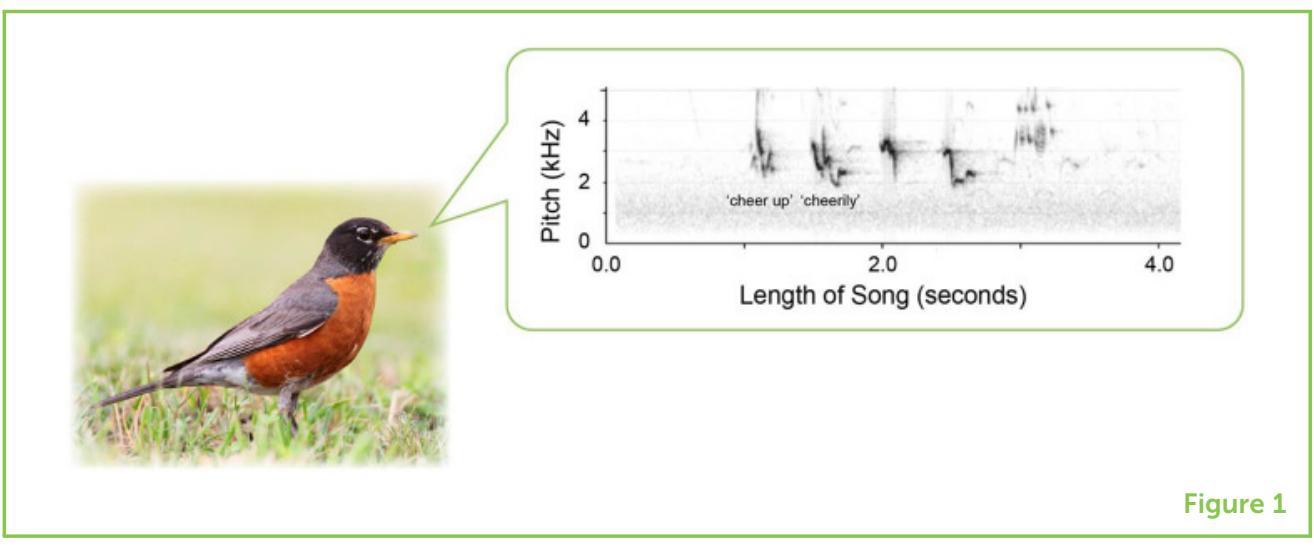

moving air through an organ called the syrinx. While you may have heard birds singing, not all birds are songbirds. Chickens and pigeons, for example, are not songbirds, and they only use short, simple "calls" to communicate. In contrast, songbirds, such as sparrows and robins, sing pretty melodies that you may hear around your neighborhood (Figure 1). Generally, male songbirds sing to attract mates and to communicate with other members of their species. Males even use songs to defend their territories from other males. Songs are an important social tool used by birds, and the ability to produce a song that can be heard easily can affect whether a bird will successfully find a partner and raise chicks.

\section{HOW DO BIRDS LEARN TO COMMUNICATE?}

Songbirds are grouped into two categories based on how their songs develop when they are young. Some species learn their songs-not in the classroom, but by listening to the adults in their population. These song-learning species are called oscines. Human babies learn to talk in a similar way; we listen and make sounds back and forth with our parents until we get comfortable with our vocal muscles. Bird species called suboscines are different because individuals do not have to learn their songs. They can sing without help from adults, which is a lot like other animals (Figure 2). Dogs do not have to learn to bark, cats do not have to learn to meow, and chickens do not have to learn to cluck! Oscines could have an advantage over suboscines when they need to modify their songs due to environmental pressures. For example, some oscines have been shown to sing louder when researchers played loud background noise nearby [1, 2]. In urban environments, singing louder in response to noise might help a bird be heard by others, and the ability of oscines to learn their songs might help them to change their songs more easily [3], but scientists are still trying to figure this out.

\section{SONGS CHANGE CLOSER TO CITIES}

Noises, like traffic or construction, may make it harder for birds to hear each other's songs. When the background noise increases around a 
Figure 2

Some birds learn their songs, and some do not! Like the way human babies learn how to speak, birds such as blackbirds learn their song from adults in their population (top). Some birds, like the black phoebe, do not learn from other birds, and can sing without any help (bottom). This would be like a baby speaking in full sentences right after birth or writing without being taught how!

\section{PITCH}

High-ness or low-ness of sound. For example, dog whistles are high-pitched sounds, while trains rumbling are low-pitched sounds.

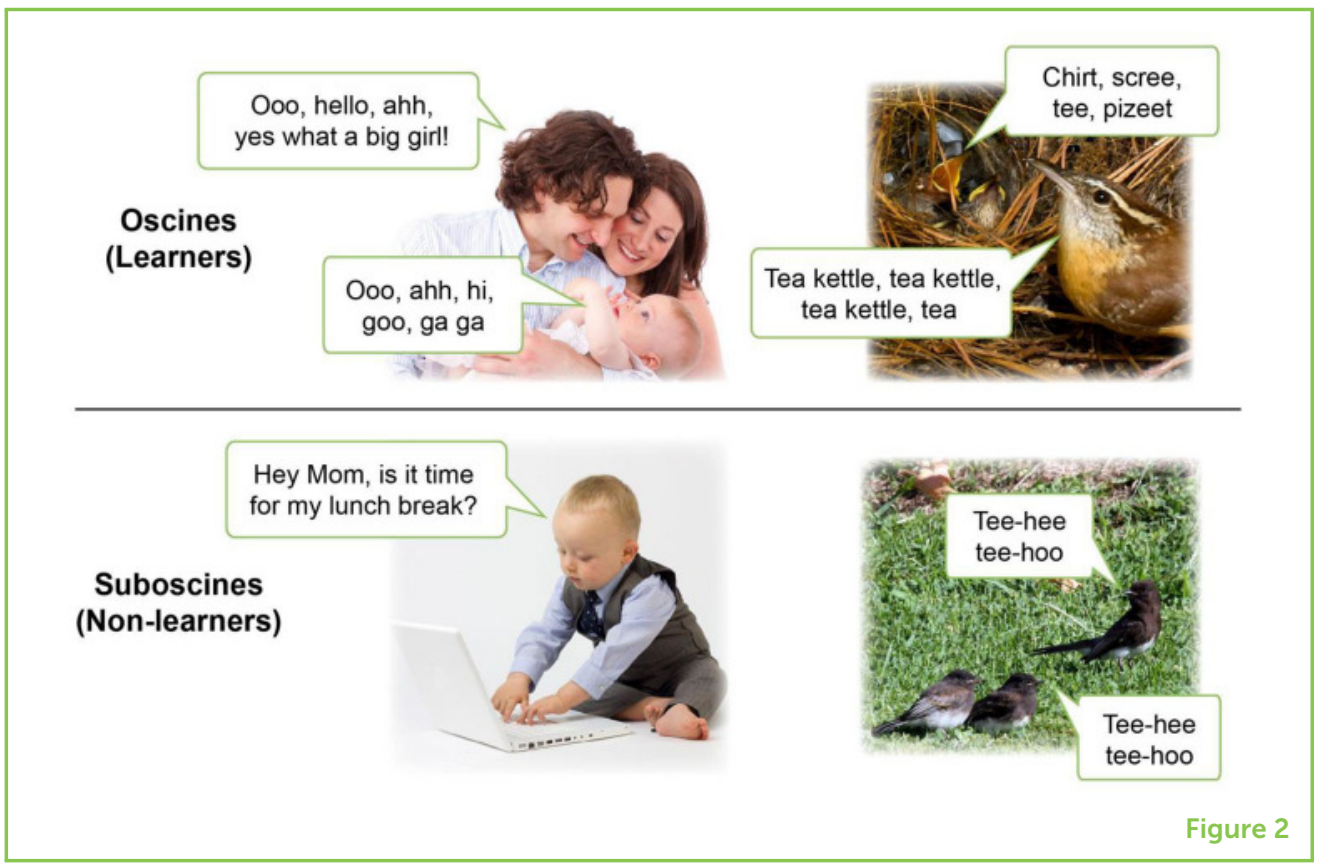

population's habitat, some birds might sing louder songs, sing for a longer amount of time, or sing at a higher pitch to be heard above the noise [4]. Scientists are currently researching if a male's ability to find mates in the city is affected by these changes in their songs, since those changes might come at a cost [4]. For songbirds, living near low-pitched traffic noise and needing to sing louder or at a higher pitch can be stressful [5]. This would be a little bit like using your "outside voice" all the time; your throat would end up sore! As a result of the stresses of urban life, scientists have seen that songbirds often choose to move their homes outside the city. The number of species living in urban areas with significant background noise has decreased, which could be related to their songs being drowned out by the city sounds [6].

Multiple studies have been done to test how birds change their songs in noisy places. One notable study recorded common blackbird songs in the inner city of Vienna, Austria and in the woods outside of the city [4]. The two blackbird populations were about 4 miles apart. The songs were measured early in the morning when songbirds most commonly sing. In the city, the pitch of the loudest part of the song was much higher than that of the rural birds in the woods (Figure 3). Singing in a higher pitch would be like making the sound of a flute instead of a tuba! The city birds sang fewer notes than the rural birds and sang much earlier in the morning, possibly to beat the loud car traffic. In the city, birds also sang faster-instead of pausing for a certain time between their notes, they would shorten these pauses and rush their songs [4].

This change in songs is also seen with many other bird species around the world! Another study analyzed the songs of 55 bird species 
Figure 3

A study in Austria supported the hypothesis that urban noise can change birds songs. Blackbirds in urban environments sang at a higher pitch than the rural blackbirds (top) ${ }^{2}$. The map shows the locations of the study near Vienna; the yellow star indicates the urban setting while the purple star indicates the rural setting.

2 Here are examples of blackbird songs from urban and rural locations in Austria (These recordings are not from the original study but were found on citizen-science databases).

Rural blackbird recording: www.xeno-canto.org/ 102018 contributed by Volker Arnold, audible at the 22 second mark. Urban blackbird recording: www.xeno-canto.org/ 106165 contributed by Christian Roos, audible at the 8 second mark.

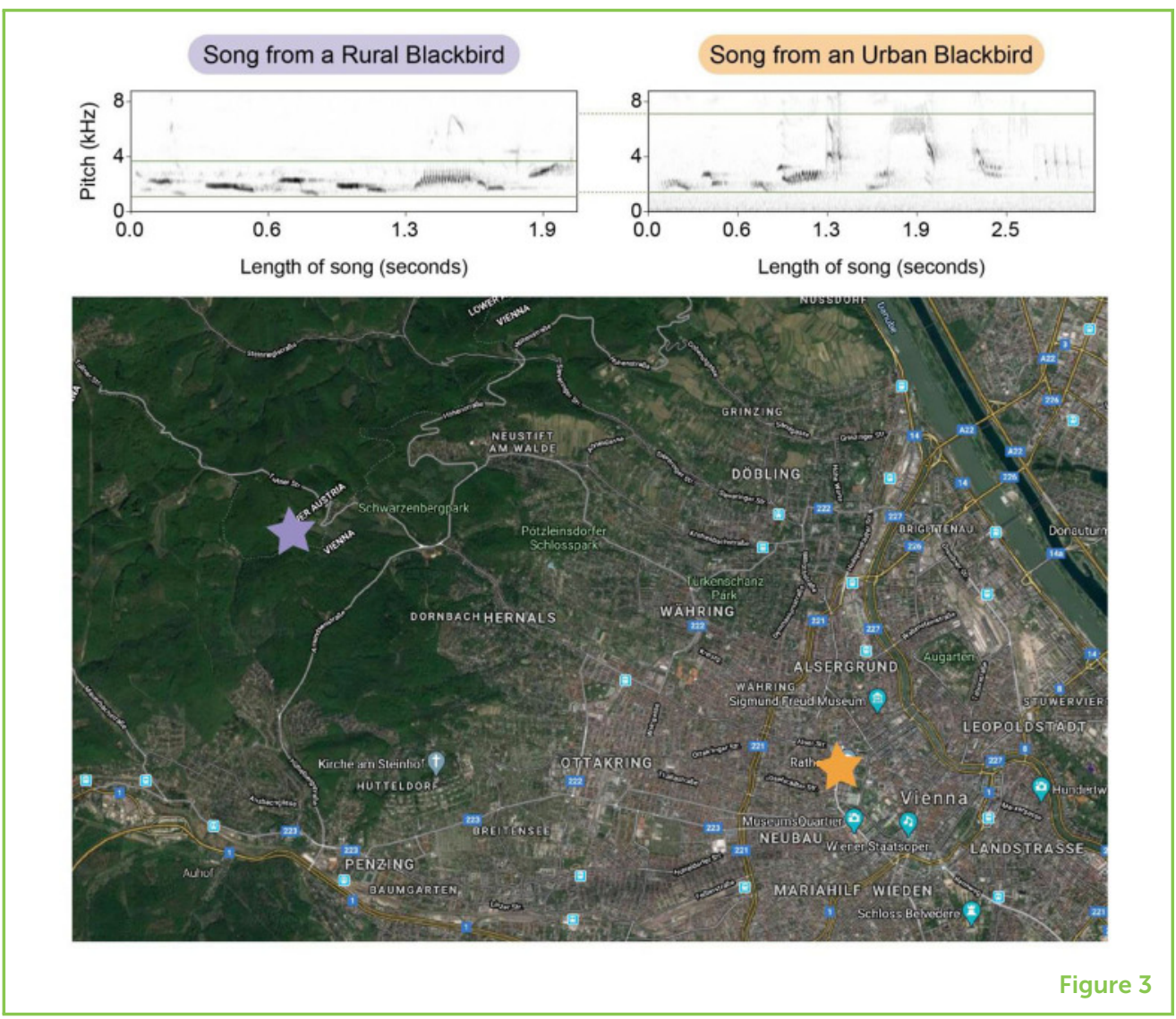

and found an overall pattern: when faced with background noise, the birds typically increased their pitch [7]. Another way birds can adapt is by singing louder, even though this takes more energy [8]. Larger birds tend to sing louder instead of changing the pitch of their songs, whereas smaller songbirds change their songs' pitch more often than larger birds [7]. Learning songs, like oscine species do, may be important for adapting to a changing environment. Since the young practice what it feels like to change notes around and listen to themselves to test their songs, songbird species that learn their songs might change their songs more easily in response to their environments than species that do not learn their songs, but more research is still needed [3].

\section{WHY DOES THIS MATTER?}

People are creating challenges that organisms must face daily. Our cities are invading areas that used to be natural habitats for many species. By building on those lands, we are affecting the organisms around us. It has been shown that traffic noise alone can scare birds away or influence them to change their songs [5]. Birds evolved their songs for the environments they live in, and as their habitats get noisier and noisier, they are adjusting many of their behaviors. It may not seem like a big deal that songs are changing in many 
bird species around the world, but if birds cannot communicate, they could have difficulty finding mates and some species may disappear forever! Humans disrupt birds' natural environments in other ways, too. In cities, artificial lighting is on all night, which does not match the natural light cycle. This can confuse birds, disrupting when they sing and how they behave. Cities can also have different diseases and new predators (like house cats) that can kill birds and reduce their population sizes.

Human activity is affecting bird migration and survival. Birdwatchers in North America and Europe have noted that fewer birds are coming back from their winter vacations in Latin America and Africa. This is important because, for example, birds eat insects, which decreases the number of insects that eat our crops. If it were not for birds returning in the spring and eating bugs, many of the fruits, vegetables, and grains in grocery stores could become scarce and more expensive [9]. We need to be aware of how human activities affect the environment around us. Decreasing the amount of noise we make would be good for the health of birds and other animals, and also for human health! In noisy areas, humans are more likely to develop hearing loss, heart issues, trouble sleeping, and general irritability [10]. People are already working on ways to decrease urban noise, such as deeper highways, noise barriers, and tunnels, to make both humans and birds healthier.

You can help, too! Research currently being done on bird song often uses recordings from helpers called community scientists-like you! Scientists can use recordings taken by community scientists to help with their research. Anyone with a phone can go outside, watch birds, and record songs on their phone to contribute to science s. $^{3}$. Maybe some of the bird songs you record will help to make the world a healthier place for both birds and the humans who enjoy their songs!

with a smartphone! https://www.allabout birds.org/news/howto-record-bird-soundswith-your-smartphonesmartphone-our-tips/ The Cornell Lab of Ornithology offers activities and other resources about bird watching, community science, and more. https://www.birds. cornell.edu/k12/.

\section{IMAGE CREDITS}

The image of the American robin (Turdus migratorius) used in Figure 1 is adapted from a photo taken by user Kristof vt (https://en.wikipedia. org/wiki/File:Turdus-migratorius-002.jpg), available under the Creative Commons Attribution-Share Alike 3.0 Unported license.

The image of the boy in a suit in Figure 2 is adapted from the photo contributed by Paul Inkles at Vision Creation (www.visioncreation.co.uk) under Attribution 2.0 Generic (CC BY 2.0) and can be found at https://www.flickr.com/photos/dumfstar/8553473662.

The image of the parents holding a baby in Figure 2 is adapted from the photo contributed by Vera Kratochvil at Publicdomainpictures.net available under Creative Commons 0: Public Domain and can be found 
at https://www.publicdomainpictures.net/en/view-image.php?image $=11263$ \& picture $=$ parents-holding-baby .

The image of the black phoebe juveniles and parent in Figure 2 is adapted from the photo contributed by Greg Schechter available under Creative Commons Attribution 2.0 Generic (CC BY 2.0) and can be found at https://commons.wikimedia.org/wiki/File:Black_ phoebe_-_Flickr_-_GregTheBusker.jpg.

The image of the Carolina wren nest in Figure 2 is adapted from the photo contributed by Kirk Olson available under Attribution 2.0 Generic (CC BY 2.0) and can be found at https://www.flickr.com/ photos/kirkols/4486843928/.

The map in Figure 3 is a screenshot taken from Google Maps.

\section{REFERENCES}

1. Derryberry, E. P., Gentry, K., Derryberry, G. E., Phillips, J. N., Danner, R. M., Danner, J. E., et al. 2017. White-crowned sparrow males show immediate flexibility in song amplitude but not in song minimum frequency in response to changes in noise levels in the field. Ecol. Evol. 7:4991-5001. doi: 10.1002/ece3.3037

2. Brumm, H., and Todt, D. 2002. Noise-dependent song amplitude regulation in a territorial songbird. Anim. Behav. 63:891-7. doi: 10.1006/anbe.2001.1968

3. Ríos-Chelén, A. A., Salaberria, C., Barbosa, I., Macías Garcia, C., and Gil, D. 2012. The learning advantage: bird species that learn their song show a tighter adjustment of song to noisy environments than those that do not learn. J. Evol. Biol. 25:2171-80. doi: 10.1111/j.1420-9101.2012.02597.x

4. Nemeth, E., and Brumm, H. 2009. Blackbirds sing higher-pitched songs in cities: adaptation to habitat acoustics or side-effect of urbanization? Anim. Behav. 78:637-41. doi: 10.1016/j.anbehav.2009.06.016

5. Slabbekoorn, H., and Ripmeester E. A. P. 2008. Birdsong and anthropogenic noise: implications and applications for conservation. Mol. Ecol. 17:72-83. doi: 10.1111/j.1365-294X.2007.03487.x

6. Proppe, D. S., Sturdy, C. B., and St Clair, C. C. 2013. Anthropogenic noise decreases urban songbird diversity and may contribute to homogenization. Glob. Chang. Biol. 19:1075-84. doi: 10.1111/gcb.12098

7. Roca, I. T., Desrochers, L., Giacomazzo, M., Bertolo, A., Bolduc, P., Deschesnes, R., et al. 2016. Shifting song frequencies in response to anthropogenic noise: a meta-analysis on birds and anurans. Behav. Ecol. 27:1269-74. doi: 10.1093/beheco/arw060

8. Brumm, H. 2004. The impact of environmental noise on song amplitude in a territorial bird. J. Anim. Ecol. 73:434-40. doi: 10.1111/j.0021-8790.2004.00814.x

9. Wilcove, D. S., and Wikelski, M. 2008. Going, going, gone: is animal migration disappearing. PLoS Biol. 6:e188. doi: 10.1371/journal.pbio.0060188

10. Basner, M., Babisch, W., Davis, A., Brink, M., Clark, C., Janssen, S., et al. 2014. Auditory and non-auditory effects of noise on health. Lancet. 383:1325-32. doi: 10.1016/S0140-6736(13)61613-X 
SUBMITTED: 06 May 2020; ACCEPTED: 10 September 2021;

PUBLISHED ONLINE: 14 October 2021.

EDITED BY: Ester Dias, University of Porto, Portugal

CITATION: Kantorek N, Searfoss A and Creanza N (2021) How Do Birds Sing Over City Noise? Front. Young Minds 9:559702. doi: 10.3389/frym.2021.559702

CONFLICT OF INTEREST: The authors declare that the research was conducted in the absence of any commercial or financial relationships that could be construed as a potential conflict of interest.

COPYRIGHT @ 2021 Kantorek, Searfoss and Creanza. This is an open-access article distributed under the terms of the Creative Commons Attribution License (CC BY). The use, distribution or reproduction in other forums is permitted, provided the original author(s) and the copyright owner(s) are credited and that the original publication in this journal is cited, in accordance with accepted academic practice. No use, distribution or reproduction is permitted which does not comply with these terms.

\section{YOUNG REVIEWER}

\section{DOROTHY, AGE: 9}

I love all kinds of science, but especially space sciences. I love reading fantasy and science fiction especially about space travel. I want to go Mars someday or at least contribute to the mission to Mars. I like playing Minecraft and Roblox with my little brother. I also love soccer, mountain biking, and taekwondo. I currently live in Germany but I am from Temple Terrace, Florida, and look forward to returning to Florida in a few years.

\section{AUTHORS}

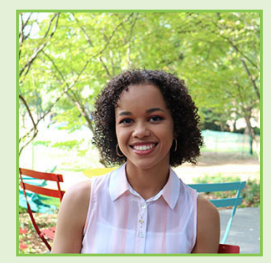

\section{NYSSA KANTOREK}

Nyssa graduated from Vanderbilt University with her bachelor's in Neuroscience with a minor in Psychology. While at Vanderbilt, she conducted research with the Creanza Lab specifically in urbanization and city noise and how that affects birdsong in species such as the northern cardinal. Currently, her project focuses on how northern cardinals in Nashville respond to sources of noise such as buildings and roads. Moving forward, she will be attending UT Southwestern Medical School to continue to pursue her interests in biology and spatial analyses as a physician.

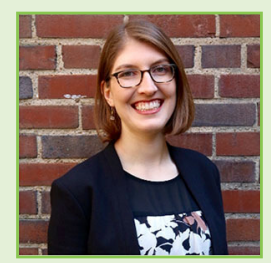

\section{ABIGAIL SEARFOSS}

Dr. Searfoss received her PhD from Vanderbilt University in 2020. Her doctoral research focused on developing new computer-based tools to break down complex bird songs into smaller pieces that can be measured and compared. She then used this computer program to study the songs of a small bird called the Chipping Sparrow. She asked questions like: Does the Chipping Sparrow's song sound different in the Eastern and Western United States? Do Chipping Sparrows sound different 


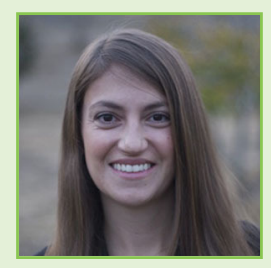

now than they did in the 1950s when people began recording them for the first time? Since graduation, Abigail has been working at an education technology startup in Nashville.

\section{NICOLE CREANZA}

Dr. Creanza is an Assistant Professor of Biological Sciences at Vanderbilt University. Her research focuses on behavioral evolution: how behaviors that have to be learned, like bird songs and human languages, change over many generations. In her lab at Vanderbilt, she works with students on to answer two main types of questions about behavioral evolution. First, if we study lots of birdsong recordings, can we find patterns-such as differences between urban and rural songs-that teach us how birds are using their songs? Second, can we build simulations (like automated video games!) that show us how the rules of the game affect how behaviors change over time? Even though bird's songs are not exactly like languages, we can ask similar questions about languages and how they have changed throughout human history. *nicole.creanza@avanderbilt.edu 